\title{
Review
}

\section{Let sing again. Of Sounds, Songs and Language in Humans and Birds}

Luisa Speranza, Umberto di Porzio

Corresponding author: Luisa Speranza, $\mathrm{PhD}$

Albert Einstein College of Medicine

Dominick P. Purpura Department of Neuroscience

Rose F. Kennedy Center,

1410 Pelham Pkwy S,

The Bronx, NY 10461

Email: luisa.speranza@einsteinmed.org

speranzalu@gmail.com

phone: +13322100542

Umberto di Porzio, MD/PhD

Institute of Genetics and Biophysics, CNR

Via Pietro Castellino 111

80131 Naples, Italy

email: diporzio@igb.cnr.it

$$
\text { diporzioumberto@gmail.com }
$$

phone +393930004888

web sites http://www.igb.cnr.it/staff/people/diporzio

https://loop.frontiersin.org/people/3831/overview 


\begin{abstract}
In million years, under the pressure of natural selection, hominins acquired vocal learning, music, language and intense cooperation, thanks to the efficacy of music in enhancing sociality. Thus, early in human evolution music became part of human life, a relevant activity, which required sophisticated perceptual and motor skills. It contributed to developing cultures and history, social bonding, and from the beginning of life strengthens the mother-baby relation while within the mother's womb. Music existed in all known human cultures, although it varies in rhythmic and melodic complexity. It is art made of sounds capable of arousing emotions, evokes memories, engages multiple cognitive functions, and promotes concentration, stimulates the imagination, creativity, and harmony of movement. Music and language share the same complex neural network. Music changes the chemistry of the brain activating the reward and prosocial systems, altruism, and allowing its use in therapy. This review explores "what" is music and illustrates the neural circuits that allow the production of music and language and those that transduce the sounds perceived by the ear, localize and archive them, allowing to recall them. Interestingly, songbirds share many commonalities with human music: common neural pathways that shape vocal learning and how they make sounds.
\end{abstract}

Keywords: Altruism, Basal ganglia, Dopamine, Emotion, Evolution, Plasticity, Social bonding. 
O gentle art, in how many gray hours,

when the wild whirlwind of life held me close

you lit my heart with warm love,

you kidnapped me in a more beautiful world!

Schubert, To music, op. 88 no. 4, D547 Fig. 1

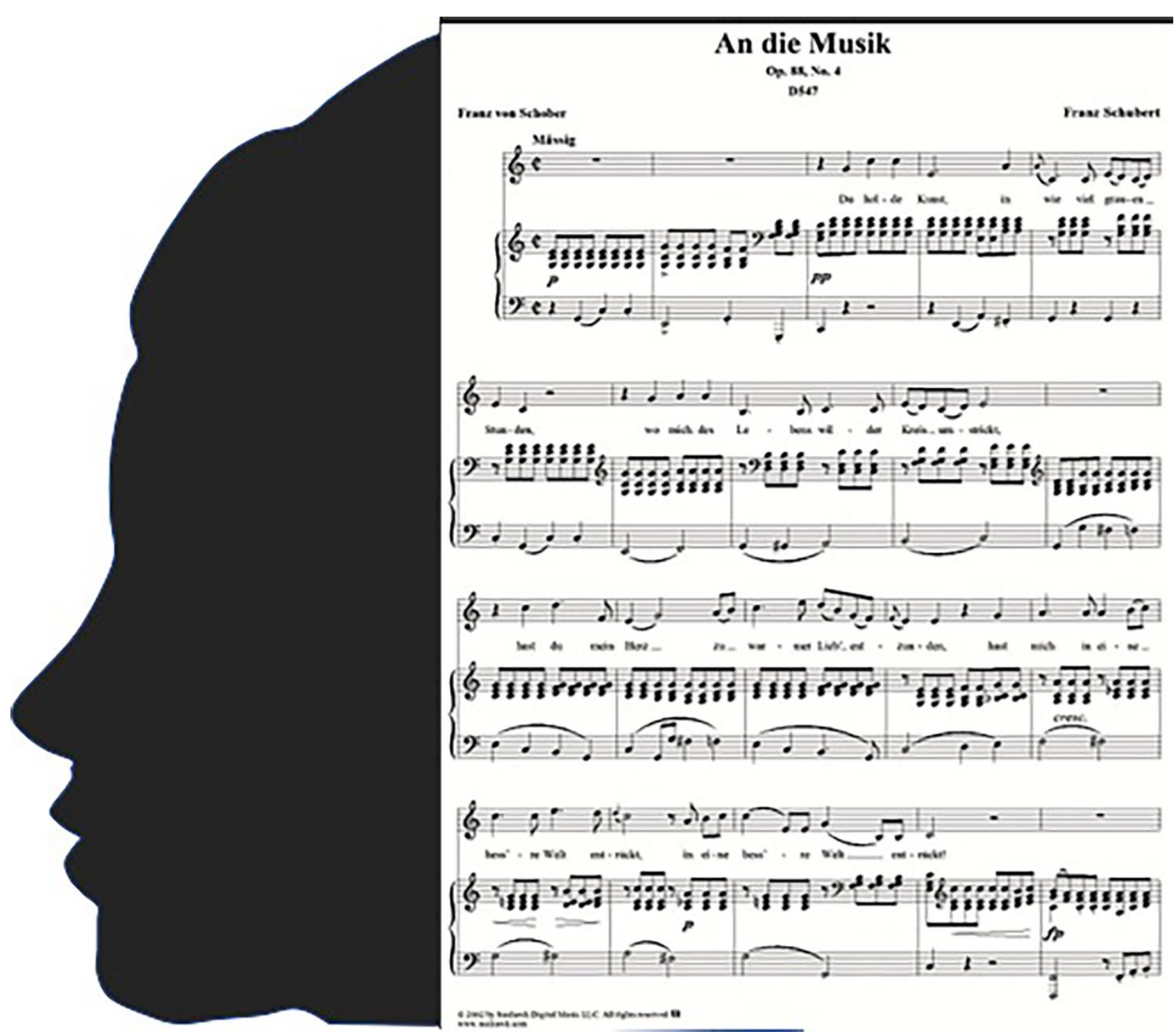

Fig. 1. Shubert's sonata To Music. A page of the music score of Schubert's sonata op. 88 no. 4.

\section{Introduction}

Music has been perhaps amongst the most ancient human activities. Music appears to be related to the essential nature of our species, and conceivably musical communication was fundamental to the life of our hominin ancestors [1]. 
It has inspired not only composers but also writers and poets, which have written beautiful pages on the charm of music and its evocative and emotional power, since music can whisk you away to ethereal worlds, such is the beauty of music ${ }^{1}$. Most music can evoke feelings including rage, emotions, memories.

Since ancient times, music has been used to accentuate spirituality, unite people for a cause, march in protests or military parades, in wars, fill us with pride, mourn our dead, and alleviate sadness and pain. Nowadays a further example is represented by "flash mobs": brief and unexpected music performances in public spaces that quickly disperse are able to harmoniously gather and connect people regardless of whether they are children, adults and elderly, showing how music has still a profound social influence [2].

Why can music be so strongly evocative and ignite intense emotions? Why and how music stimulates communal feelings and bonds? Is it true that music does not have an adaptive function or survival value? Indeed, neither of these two assumptions is confirmed by recent studies on its social role and altruism.

Music affects many areas of the brain and musical training can significantly improve both motor and reasoning skills and working memory [3]. According to David Byrne (guitarist and songwriter of the iconic band Talking Heads) "music has a liberating, life-affirming power" [4].

Questions related to memory, perception, creativity, arise when affording why we love music. Indeed, what is music? Where does it come from? Why do some sequences of sounds transport us, while others leave us unmoved or uncomfortable?

$1 \quad$ Here are presented two out of a myriad of examples of splendid pages on the evocative power of the music, how it can make sadness or beauty and joy visible, lead us to the sublime or to impenetrable anguish: "But suddenly it was as though she had entered, and this apparition tore him with such anguish that his hand rose impulsively to his heart. What had happened was that the violin had risen to a series of high notes, on which it rested as though expecting something, an expectancy which it prolonged without ceasing to hold on to the notes [...] And before Swann had time to understand what was happening, to think: It is the little phrase from Vinteuil's sonata. I mustn't listen! all his memories of the days when Odette had been in love with him, which he had succeeded, up till that evening, in keeping invisible in the depths of his being, deceived by this sudden reflection of a season of love, whose sun, they supposed, had dawned again, had awakened from their slumber, had taken wing and risen to sing maddeningly in his ears, without pity for his present desolation, the forgotten strains of happiness." (Proust 1913).

"A sweet, passionate melody spoke to the heart with its very first notes. It seemed all thoroughly replete with sparkling light, fraught with inspiration, with beauty, and with joy. As it rose and sank it seemed to speak of all that is dear, and secret, and holy, on earth. It spoke too of sorrow that can never end, and then it went to die away in the distant heaven." (Turgenev, 1858). 
What is music it is difficult to say, perhaps the definition would vary from individual to individual. One that we like to share is that music is sounds that arouse emotions, the establishment of human relationships, which directly touch the feelings, the affects.

The emotional and evocative meanings of music probably differ from place to place, that is the sites where music is performed, as well as the audience, have a certain impact on our musical experience. In other words, there is a resonance between brain, music, places, and in general, the ambiance, the site, and the musical pitch are closely linked since music moves in a physical space and the spaces are resonant. Listening to music or play in a concert hall or an opera house, live atonal music experience in special places as the Piscina Mirabilis in Miseno (a Roman reservoir of the 1st century AD near Naples, Italy, with vaulted ceilings, pillars, and arcs that resembles a Gothic cathedral[5]) or a concert in the Greek theater of Segesta or Delphi, as well as hear rap in the streets of New York, play or listen to Mozart's music in the incomparable atmosphere of the enchanting small concert hall 'Sala Terrena', in the Mozarthaus in Vienna, where Mozart himself performed many concerts, all that establishes a resonance between our brain, our senses, and the places that gives an emotional and evocative meaning to music and sounds probably peculiar in each place. And apparently it is more so for performers.

Music is not just sound, it is also silence, as John Cage wanted to demonstrate in his renowned 1952 composition 4'33" in three movements of silence. Also, we could say that the sound of silence can activate the auditory cortex, as when we repeat a phone number or "hear a tune" in our head, imagining music without actually hearing it, or musical imagery [6]. Indeed, the inferior frontal gyrus is involved in generating speech and music in our mind independently of auditory perception. The speech center Wernicke area (see below) interacts with the auditory network both during musical perception and musical imagery, through bilateral interactions contradicting the conventional notion that music and language are processed separately in the two hemispheres [7].

\section{Music in Cultural Contexts}

We still need to elucidate several biological foundations of human musicality and to define the relationship with the cultural traditions in which they developed and are practiced.

Generated in specific social and community contexts, musical experience can also play a role in the formation and affirmation of distinct individual and collective identities. Some music acquires a symbolic value such as national anthems, protest songs, or religious hymns. The songs of a distant homeland keep alive the feeling of belonging of the emigrants.

The great movement of American and British rock in the 1950s and 1960s gave voice to an entire generation that broke with the values of the fathers' society. Listening, dancing, and perhaps 
performing punk music rather than techno or heavy metal may represent some of the young person's lifestyles and values today. Therefore, music seems to be able to unite souls wherever they are and transcend individual realities. Music often interprets the prevailing cultural trends in a given historical moment and even more often anticipates their overcoming. However, although music appreciation may depend on the cultural background, the enjoyment of music can be cross-cultural, as new data suggest that the musical quality of a sound is recognized by the human brain regardless of whether or not it belongs to the native culture of the listener. For example, a recent study involving people from 60 countries who listened to 86 different songs showed that they deduced the song's features based on the form [8]. Therefore, music, while maintaining a strong variability between cultures seems to have recurrent, distinct, and recognizable form-function relations, detectable by listeners across the globe, which depend on intercultural aspects of human behavior. Indeed, while the personal emotional response may be mediated by cultural history, there is a universal answer to the most basic features of music [9].

Such a "trans-cultural" appreciation of music is historically proven by the fact that in China western music was appreciated since the 16th century when the Jesuit Matteo Ricci brought a clavichord to Emperor Wanli, of the Ming dynasty, to perform western music. In China, today there are tens of millions of students studying and playing western music, and many great western music performers are of oriental cultural origin and education [10]. In recent years Puccini's Turandot has become very popular in China. In the sixties, Indian music became very popular in western culture thanks to the music of the Beatles, and in particular, to the piece Love you to in the 1966 album Revolver, and later to the Indian sitar musician Ravi Shankar.

However, it should be noted that most musical studies have focused on western tonal music, which may have led to a one-sided view. Many listeners and performers also appreciate atonal music, although this lacks a tonal hierarchical structure, which is dissonant and difficult to predict. Still, it can express a whole "new range" of emotions and soundscapes. It can add a surprising element. With the evolution of sound transmission and technology, from Edison phonograph cylinders of the late nineteenth-century to MP3, there have never been more opportunities for music and musicians to reach such large and heterogeneous audiences as today. We live in a world overloaded with music, with all types of music available most of the time at our will. However, today music floods all kinds of public spaces, such as lifts, supermarkets, taxis, restaurants, in some cases even city streets; it is not meant to convey a specific message but instead often overwhelming marketing. It cancels the very idea of listening and the assumption that music is a form of communication, and it doesn't elicit emotions. 


\section{Music and Human Evolution}

Music communication, as the archaeologist and anthropologist Steven Mithen claims, was essential for the life of our hominin ancestors. In other words, music is part of our evolutionary legacy [1], although it does not serve an obvious, uncontroversial function, a part perhaps to be part of audio and visual warning signals to scare away aggressors and predators [11]. Initially, there may have been a communication system closer to music than language, a "prosodic protolanguage". The human language would derive from the vocal references of baboons, gibbons, and cercopithecines, which present elements that characterize some aspects of language, as Darwin himself had speculated [12]. In particular, there existed a "Hmm" language, that is holistic (they can form complete messages, rather than single words), manipulative (aimed to condition the behavior of others), and musical (characterized by rhythm and melody). Multimodality (the combined use of vocalizations and gestures), which belongs to the communicative repertoire of the great anthropomorphic apes, must also be added to these three elements (Hmmm). Thus, early hominins communicated by a Hmmm system through variations in rhythm and intonation. This theory disproves the long time accepted notion that language began with a gestural protolanguage [13]. Understanding the emotions and mental states of others would become increasingly important as human communities became more dependent on their social network to hunt and survive. In addition to being a means of communication, singing and dance became fundamental for the emergence of social life. With the development of bipedalism and the change of the neck (lowering of the larynx and lengthening of the vocal tract), wider and more melodious vocalizations could be realized. Neanderthals apparently had a musical proto-language combined with the dance described as "Hmmmmm", holistic, multi-modal, manipulative, musical, and mimetic [14]. Then the protolanguage split into two forms, what we now call music and language.

Language has become the main method of transmitting information, while music has remained a means of emotional communication, which also facilitates social bonding. "Music was essential to the survival of our ancestors, and we inherited their need and pleasure", that is, in the course of evolution, music has acquired the function of synchronizing feelings, emotions, and actions [15]. Like music, dancing is present in all human cultures. Indeed, in humans, there is a strong tendency to perceive musical tempo and synchronize body movement with the rhythm of a regular beat. Recent results suggest that music automatically activates the regions of the brain involved in initiating the movements necessary for singing and dancing. In experiments of magnetoencephalography with a volunteer pianist, it has been shown that listening to a piece of music triggers involuntary motor activity involving the contralateral primary motor cortex [16]. 
More recently it has been observed that this is also true for non-musicians. If we ask a volunteer during a functional magnetic resonance imaging session (fMRI) to remain completely still while we play music, we will see that his motor cortex is activated, despite the fact that the individual is not in motion. That is, our brain shows activity in areas of the cortex that control movement even when we try to actively inhibit the tendency of music to make us move. The linking between the auditory and motor brain region is strengthened in musicians, thus they are plastic.

Given the strong interactions between auditory, motor, visual, and mirror systems (see below), very probably music and dancing developed together and increased social bonding in early human societies, strongly contributing to the evolution of modern humans.

\section{Music and Language}

There are common and divergent aspects of sound and language. A common aspect is the melodic character of emitted sounds.

For instance, the rhythm seems to dominate in music, it also determines some structures in language, and in the metric verse.

Both language and music have rules for ordering notes, chords, and intervals that make up the syntax. It is the combination of these elements which constitutes melody in music and prosody in language. Language is made up of symbols (words) held together by rules (syntax) to form larger significant units (sentences). The music melody conveys emotional meaning, evokes deep, and often shared primordial feelings. Listeners easily detect emotions transmitted in musical idioms, including unfamiliar ones, especially happiness, and sadness. A higher, more variable tone, faster tempo, and rhythm, communicate happiness, whereas the opposite conveys gloom.

These same characteristics - intonation, rhythm, and tempo - are used to convey emotions in the language (the prosody), in a way that seems to be general in all languages.

Despite these important similarities, a fundamental difference between language and music lies in the fact that the linguistic units, the lexemes or lemmas, are part of a finite repertoire with fixed rules of combination, independently of the type and number of speeches that the system then allows generating.

The musical note, on the other hand, is the unity of sound but takes value only in the range that sets the note paradigm. Unlike language, the musical language is a system of non-significant units. As with other artistic systems (painting for example), the semantic system manifests itself in the compositional complexity, at the level of the global effects.

\section{Brain Development and Music}


However, to listen to music and perceive the emotions it transmits, you need to have a brain and tools for the sound to reach it. Notwithstanding, there is no one specific area in the brain that processes musical information. Instead, there is simultaneous and coordinated activation of several neural networks in the temporal lobe (listening, language), frontal lobe (abstract thinking), subcortical structures, such as the cerebellum and basal ganglia delegated to motor control and the choice of motor patterns, which seem implicated in the perception of rhythm, up to the most complex areas of emotions in the processing of tonality and rhythm, according to a functional hierarchy, Fig. 2.

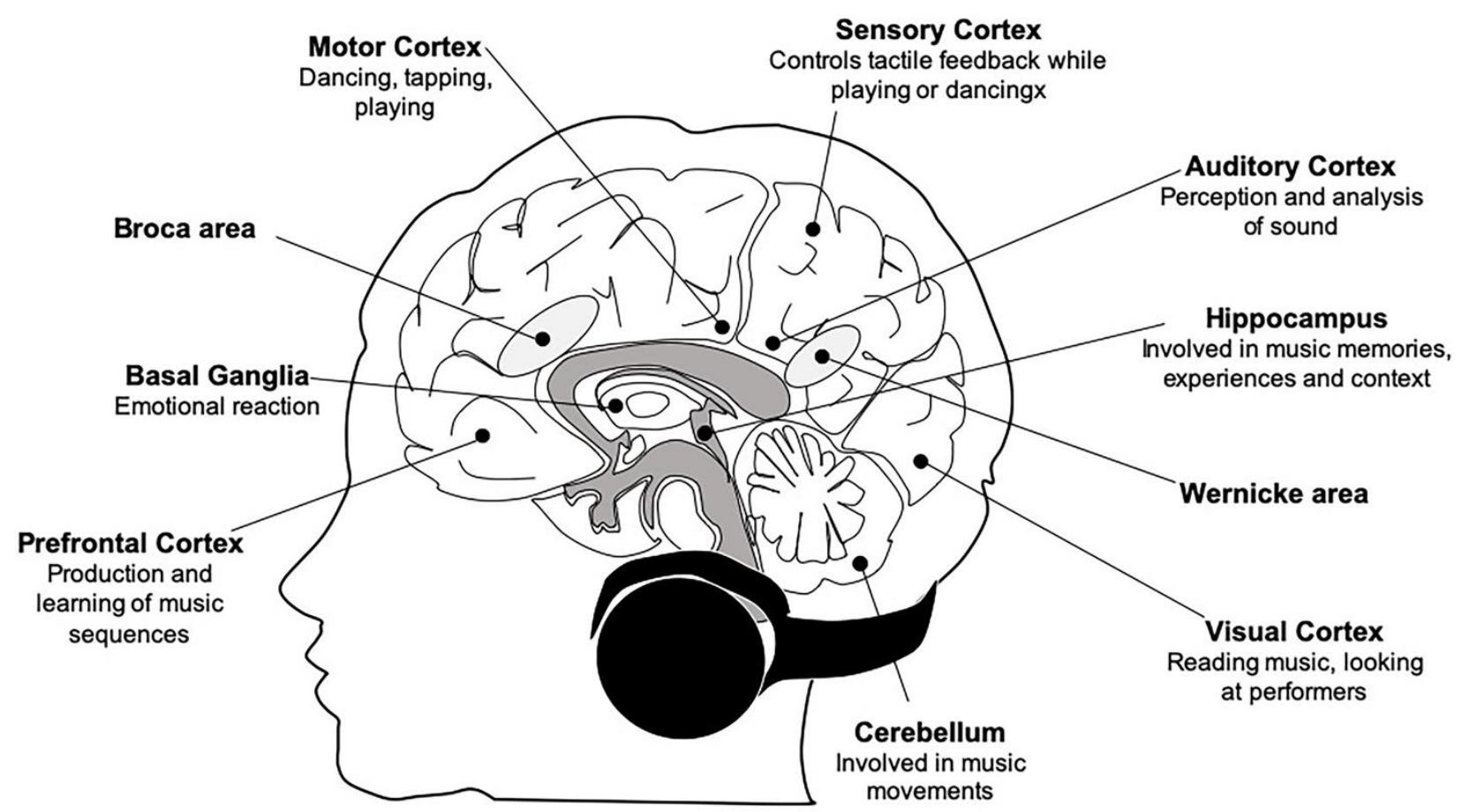

Fig. 2 The areas of the human brain involved in music. Schematic representation of different areas of our brain implicated in listening and playing music.

The brain is extraordinarily complex: in humans, it contains about eighty-six billion neurons and the number of possible interconnections should be multiplied, according to some estimates, by a thousand or ten thousand. Of all these neurons about $20 \%$ are concentrated in the cortex, and it is here that "cognitive" functions and sensory processing are based.

This complexity is further expanded by the nature of the brain circuits which are not connected in a fixed, "hard-wired" way, but are widely modifiable with experience. Certainly, there are portions of the brain that are genetically determined, so that structures and functions are common to the individual of each species. We know now that the brain has great adaptability exercised not only 
during embryonic development, where it is expected, but also in adulthood. Indeed, the characteristics observed in the adult brain reflect embryonic development. Brain development is "activity-dependent" in the sense that activity in every circuit - be it sensory, motor, emotional, cognitive - shapes the way that neural circuit works.

Newborn neurons migrate and establish synapses, the specialized junctions deputed to communication between neurons. Those cells and connections that are used will survive and thrive. Those cells and connections that are not used will wilt and disappear.

Over time, the brain continues to shape itself while the basic structures of the brain are forming, establishing and retrieving new synapses (pruning). Synaptogenesis is a complex process that involves the differentiation of the pre- and post-synaptic membranes, with the concentration of receptors and vesicles (which contain the neurotransmitter to be released), the introduction of localized protein synthesis, and biosynthesis of cholesterol, necessary for the formation of lipid rafts [17]. Cell adhesion molecules, trophic factors, in particular, BDNF (brain-derived neurotrophic factor), morphogens such as Wnt7a and Wnt2 members of the Wnt family (Int-1 and wingless genes in mice and Drosophila, respectively), long non-coding RNAs, and several other gene products contribute to synaptogenesis in the central nervous system as well as in the periphery (e.g. neuromuscular junction). Amongst the various genes involved, it has been recently identified Prl-1 (membrane-anchored phosphatase of regenerating liver gene) that promotes axonal synaptogenesis in Drosophila [18]. However, many players in synapse formation may also be involved in neurodegenerative diseases.

During evolution, the human brain had enlarged, about tripled in size, and a larger brain also required a larger skull, with the risk that the fetus would not adapt through the mother's pelvic canal. The latter, to adapt to erect walking, had become narrower, too much for the passage of a large head at birth. However, at birth the human brain is small and the skull is also malleable. The skull is made up of several bones, joined by sutures that are not yet welded at birth, so the human baby's head is elastic, allowing it to pass through the birth canal. Only later does the skull undergo progressive growth suitable for brain development. The human brain at birth has a size equivalent to approximately $28 \%$ of the adult, and it continues to grow up to 25-28 years of age. Thus, a large part of the brain wiring develops after birth as individuals grow interacting with a rich physical and cultural environment and are exposed to a wide range of stimuli. The last part of the human brain to complete the development of its connections is the frontal lobe, which governs attention, impulses, and motivation. Just before puberty, and thereafter, there is a new proliferative wave at the level of the prefrontal cortex (PFC;[19]) responsible for cognitive analysis, abstract thinking, and behavior 
moderation. It integrates various sensory information and orchestrates thoughts and actions to achieve specific goals. PFC is also the area that supports autobiographical memories that music can evoke and retrieve, in other words, vivid and emotional memories of lifetime periods and events that music can bring back [20]. It is worth noticing that many brain systems are capable of learning and storing information. Interestingly sex hormones (estrogen, progesterone, and testosterone), play a crucial role in myelination, and while glutamatergic neurotransmission predominates, gammaaminobutyric acid (GABA) neurotransmission remains under construction, and this might account for some impulsive behavior and neurobehavioral excitement during adolescent life [21]. Therefore, during early postnatal development, some precise patterns of functional connections are established in the brain in part based on the individual experience. A generalization that emerges from studies on brain development is that few choices are incontrovertible. In adulthood, the brain retains a significant capacity for adaptive changes necessary to continue interaction with the environment, integrate external experiences with the formation of neural circuits responsible for behavior, and the formation of new memories. This experience-dependent plasticity is considered the basis of learning and memory and cognitive functions, it is very helpful also for recovery from brain damage and disease, but could be responsible for age-related cognitive decline, and as we will see below, this plasticity is crucial for musical and language learning, performing and listening. Thus, during childhood and in the brain of adult mammals the brain wiring is flexible. In addition to the formation of new synapses and new circuits, sometimes existing neural circuits established for a purpose can be exploited or recycled in different uses, often without losing their original functions. An example is offered by the music and language. It is conceivable that neural circuits evolved for musicality may have been recycled during evolution for language, or vice versa. This is another example of brain plasticity and is this plastic ability that allows the birth of new neurons in the adult brain and their integration in neural circuits.

The adult neurogenesis dispelled a so-called "dogma" of neurobiology which had mistakenly led to the denial of the existence of stem cells in the adult brain, as discussed in the following paragraph on songbirds [22], [23].

Chemical neurotransmitters pass through the presynaptic end of the axon to the postsynaptic membrane of the adjacent dendrite or somatic cell targets. The chemical messengers excite or inhibit electrical activity in the postsynaptic cell. As mentioned, synapses not only are not fix-wired but can be strengthened or weakened according to the activity or its lack. This synaptic plasticity can elicit an amplified response in the post-synaptic cell giving rise to the long-term potentiation (LTP) producing faster and more efficient signaling between cells at the synapse, as during learning 
and memory in the hippocampus. In turn, the LTP is opposed by the LTD (long-term depression), which reduces the effectiveness of the synapse, often to allow the recovery of the synapse after LTP.

Through synaptic connections, brain cells form the neural circuits that allow sensory, motor, and cognitive activities and ultimately regulate body homeostasis and behavior.

In theory, each neuron can establish up to ten thousand synapses with other nerve cells and receive as many. The number of possible combinations is therefore immense. However, the nervous system "seems to be constructed as if each neuron had in itself the awareness of its place in the system" [24]. The tenet in developmental neurobiology is that nerve cells acquire their unique identities and establish their ordered and precise synaptic connections based on the activity-dependent refinement (pruning) of synaptic connections, and the elimination of connections and neurons initially produced in large excess, through a specific process called apoptosis (from the Greek "falling of the petals"), or programmed cell death (PCD). The latter is activated in part by competition for trophic substances produced by post-synaptic or adjacent cells in limited quantities, which triggers the activation of a chain of genes that sustain the presynaptic neurons. Their deprivation leads to the death of the cell and thus determines the removal of many neurons. Also, other mechanisms such as the formation of free or oxygen radicals, DNA damage, activation of specific receptors as, for example, the neurotrophin receptor p75NTR, and other stress factors induce PCD by damaging mitochondria. The latter activate member of the $\mathrm{Bcl} 2$ gene family, which trigger the activation of cytochrome c (encoded by the CYCS gene) from mitochondria. This, in turn, binds to the apoptotic protease-activating factor-1 (Apaf-1) in a complex that activates several cysteine proteases named caspases (Cas9, Cas8, and Cas10) that bring the neuron to death [25], [26]. However, the neuronal apoptotic pathway is highly restricted in mature neurons, except in certain pathological contexts [27].

Therefore, we could say with the eminent Spanish neurobiologist Santiago Ramon y Cajal, Nobel Prize in Physiology and Medicine in 1906 with Camillo Golgi, that "the innumerable intercellular processes and connections present in the adult nervous system can be interpreted as the morphological expression of the infinite itineraries traced in space by currents of positive inductive or chemotropic substances during the entire developmental period. Therefore, the total arborization of a neuron represents the graphic history of the conflicts suffered during its developmental life" [28].

\section{Music and the Human Brain}


All our sensations, auditory, tactile, painful, etc. depend on cells specialized to capture and translate the different stimuli, the receptors. The different receptor signals are converted into a single type of electrical signal. The specialized receptors connect with different brain areas competent to process specific sensory information. Hearing is due to the creation of sound waves that are received by the ears, which distinguish the volume of a sound stimulus, that is determined by the amplitude (or intensity), sound waves of greater amplitude produce louder sounds. The frequency of a sound wave instead codifies the tone, the higher frequency sounds have a higher tone. We can also measure the quality, or timbre, of a sound.

The ears break the sound waves into smaller individual components and transduce them into nerve signals, allowing us to distinguish the different frequencies of sound that make up the individual notes, the different tones of music, the musical combinations (harmonics), or noise.

Music is a demanding activity, which requires multiple actions with very precise timings, the control of the range of tone, timbre, rhythm, and intonation.

Specific circuits allow the production of sounds, singing, and language and enable the mind to perceive and analyze the sounds captured through the ear, locate, and memorize/remember them. Although sound, song, language seem peculiar to the human species, they are indeed relatively widespread in the animal kingdom, where they intervene in courtship, aimed at the reproduction of the species, as a group call and recognition, as environmental learning, warning, alert sightings of predators.

Language and music are ways of communication, which occurs also through visual, hearing, chemicals (pheromones), or tactile signals. Birds or mammals are not silent, even the snake has its hissing, and some sea animals sing with a vague resemblance of a voice. But even the songs of certain birds, which are the closest to human music, only remotely approach the complexity and diversity of human music. The human language probably derives from voice calls of baboons, vervet monkeys (Chlorocebus pygerythrus) as well as gibbons (family Hylobatidae), which have elements that remind some aspects of human language and song [29], [30]. Gibbons are small apes that are bipeds and monogamous, they emit characteristic species-specific duets or solo songs, in defense of resources, to attract a mate, to establish a close relationship with the courtship and sexual activity and for group cohesion. They sing loud, melodious, penetrating pure tone reminding of a professional human soprano singing [31], [32].

In general, these warnings are holistic, manipulative, musical, and multimodal similar to the Hmmm of early humans. 
As discussed below, music has been advantageous to our species since it contributes to group bonding [33]. Only a few mammals and birds develop strong, lasting cooperative relationships amongst unrelated adults, as humans.

As fascinating hypothesis is that music was the initial way of communication for the human species, preceding verbal language, thus confirming the hypothesis that ours is a "musical" brain.

Already Darwin (1871) postulated a close interconnection in the evolution of music and language, assuming that music or singing came first. The communication between mother and baby seems to be primarily musical. Children seem to have an innate willingness to understand words and music and respond to tone and melody very soon. They recognize songs played for them for several days and quickly learn sounds relevant to voice and music as if there is an innate propensity to enjoy music. How this can produce exceptional individuals like Mozart, musicians' families like the Bachs, or the Jacksons, to give some examples, remains to be discovered.

That music was an ancient companion of humanity is attested by the discovery of the oldest musical instrument, a flute (Divje Babe flute, from the name of the cave where it was found in Slovenia) made from a bear femur, with three holes and a sharpened rim for the mouthpiece dates back to around 50-60,000 years ago, which could have belonged to both the Neanderthals and the homo sapiens, the so-called Cro-Magnons [34]. Other early flutes were found in France and in southwest Germany were discovered eight flutes from three different sites. That Divje Babe's flute is the oldest identified musical instrument does not mean that it was truly the oldest musical device. Others made from less durable material must have been lost. On the other hand, it has to be bear in mind that at the very early beginning, the voice must have been the predominant medium through which our ancestors created their music and sound scenarios. In addition, sound objects and musical instruments of any kind could have been used, however, most of these would not have survived long enough due to the highly perishable nature of the materials used, such as wood, bark, carved plant stems, animal skins, tendons, etc. Some sound stones, such as stalagmites, might have been used, or rattles made from animal teeth or shells, or mammoth bones hit with clubs. It seems that mammoth shoulder blades and femurs had excellent acoustic properties.

While Darwin hypothesized that the appearance of a "musical" man was the result of the processes of seduction between the two sexes, as in birds, modern ethnomusicology believes that human dance and song did not initially have aesthetic or reproductive purposes, were aimed instead at influencing reality was intended to propitiate and/or to evoke. The music captures something deep, symbols, and stories, in the subconscious that unite and gives emotions, joy, or sadness. 
Music played or listened to has many benefits for physical and emotional well-being, is highly motivational, brings people together to share experiences and creates bonds. Coupled with dance, it improves many aspects of human existence, both individually and in groups. It is as if we were genetically "wired" to move in rhythm and "programmed" to respond when other people sing or dance. That is, music places the individual in collaboration with other human bodies and minds. Communication that does not need words to create rich and stimulating narratives. This ability to create meaning with others through structured narratives without words emerges in the behavior of vocal and gestural games between babies and mothers or caregivers.

Singing, music and dance were probably initially instinctive, intuitive, and passed to others through demonstration and observation, from person to person, from tribe to tribe, from generation to generation, long before writing. Initially, there were the voices of people and rudimentary percussive instruments, then men began to create "instruments" from wood (hollow trunks, blocks, etc.), agitators made from seeds and peels and shells or sand. The unifying role of music has also been seen in recent centuries when slaves from different African tribes were kidnapped and transported mainly to the Americas, stripped of everything and randomly mixed, having no common languages they used percussion and songs and dances as a way to bind, connect, form, and maintain communities and social groups.

Indeed, the music changes the chemistry in the brain, inducing the release of neurotransmitters (namely dopamine and serotonin), that activate the reward system and hormones that increase bonds [35]. As Levitin argues group music and singing increase the production of oxytocin in the brain [36]. This peptide, together with vasopressin, is produced and released by neurons of the hypothalamus (specifically by the magnocellular and parvocellular neurons of the supraoptic and paraventricular nuclei) and released into the circulation through the pituitary gland. The two hormones regulate social ties, especially sexual ties, maternal attachment to offspring. They also mediate association and therefore social bonds, hence the role in social cohesion and belonging played by music. Interestingly, the receptors of these neuropeptides are more abundant in the basal ganglia of the prairie voles (Microtus ochrogaster), which are monogamous, then in the mountain voles (M. montanus) which are promiscuous [37].

Notwithstanding, monogamy amongst human has more complex bases and more multifaceted origins than simply increase or decrease of vasopressin receptors. The evolutionary origin might be linked to the need to reduce the risk of infanticide by other males, probably together with the need to provide prolonged parental child care, easier in pairs, and perhaps the need to protect the mother who is committed to growing the children, and therefore of the offspring. 
It is well documented that music stimulates the brain reward system, composed by the brain structures that form the limbic network or the cortico-basal ganglia-thalamo-cortical loop (see below). The reward is determined by desire or anticipation, linked to the activation of the dopaminergic pathways (nigrostriatal and mesocorticolimbic), followed by a satisfaction or consumption phase, due to the activation of both dopamine and $\mu$-opioid receptors [38]. That is, it is a form of associative learning, which is the association between two stimuli (i.e., classical conditioning), or between a behavior and a stimulus (i.e., operant conditioning). Endogenous opioids are implicated in the pleasure obtained from food, drugs, and sex. Both desire and gratification depend on the nucleus accumbens (NAcc), which processes the expectations of reward. Basically, musical pleasure (from pleasant music and surprising musical events) comes from the positive reward prediction errors when what is heard turns out to be better than expected, by activating the NAcc. The opioid system is responsible not only for positive responses to (pleasant) music but also for negative ones such as sadness, or aggressive thoughts and behaviors can be elicited by violent music lyrics [39],[40].

The limbic neural network is very important for the survival and reproduction of individuals and of the species. It is, as previously mentioned, activated by food, sex, social contact, the so-called primary reinforcements. It strengthens the decision-making mechanisms by comparing the values of the different choices available and possible errors, elaborating predictions on the outcome, and making choices efficiently more valid. In other words, the limbic circuit is involved in motivation and reinforcing behaviors. A key element of the reward system is represented by midbrain dopamine neurons, that signal potential upcoming reward and encode the degree to which an outcome matches expectations; thus, the strongest response occurs to outcomes that are better than expected, providing a positive prediction error signal that helps future predictions [41]. The areas of the brain involved in the pleasure deriving from music, i.e. those of reward processing, motivation, and expectation, are similarly active in drug addicts in response to stimuli related to substances of abuse, pathological gambling, and in compulsive sexual or eating behavior. They are the midbrain dopaminergic systems, the ventral striatum, the anterior cingulate cortex, the orbitofrontal cortex, and the amygdala [42]. The ventral striatum is involved in the processing of reward and motivation, the dorsal part of the anterior cingulate is involved in anticipating reward and craving (the irresistible desire to take a substance), and the amygdala participates in the processing of the meaning of events and emotions. Interestingly, an "abstract" reward as pleasure listening to music uses the same route as more tangible rewards, such as sex, food, drugs, gambling.

From Ear to Perception 
Music-brain relationships, as mentioned, involve many brain functions such as perception, action, cognition, emotion, learning, and memory, and therefore contribute to the understanding of how the human brain works and how various brain functions interact and to study neuronal plasticity.

Before a musical speech or phrase can be perceived and integrated with the memorized linguistic representations, the acoustic signals must be represented through a neural code and "delivered" to the auditory cortex (AC) with temporal and spectral precision by subcortical brain structures. Such subcortical preprocessing involves many distinct regions and a dense network of nerve connections. How and where is sound perceived? Sound waves travel through the outer ears. Once the waves reach the end of the ear canal, the tympanic membrane (eardrum) begins to vibrate transforming the energy of sound waves into mechanical energy. The vibration of the eardrum starts the movement of the three small bones in the middle ear, the hammer (malleus), anvil (incus), and stirrup (stapes). The malleus, which is attached directly to the eardrum, moves immediately in response to vibrations. This movement in turn moves the other two ossicles, transducing mechanical energy in the form of hydraulic energy. This fluid stimulates the ciliated internal (about 3,500) and external (about 20,000) hair cells on the basilar membrane of the cochlea, a spiral-shaped structure, which converts hydraulic energy into electrical signals. These auditory receptors constitute the organ of Corti. The hair cells connect to the spiral ganglion neurons, whose axons form the auditory component (cochlear) of the vestibulocochlear nerve (VIIIth cranial nerve). Most spiral ganglion neurons receive afferents from a single hair cell and respond to sounds within a precise range (characteristic frequency). The cochlear nerve leads the signals to the brain for further processing. The brain can process sound by determining where the signal in the cochlea comes from. The base of the cochlea perceives higher frequencies while the apex is sensitive to lower frequency sounds. From here on, briefly, the auditory path goes from the spiral ganglion to the dorsal and ventral cochlear nucleus of the brain stem, then to the inferior colliculus (midbrain) to arrive at the medial geniculate nucleus (MGN) of the thalamus. From the inferior colliculus, it passes also to the superior colliculi activating auditory-visual integration. Axons from the MGN project to the primary auditory cortex in the temporal lobe through the so-called acoustic radiation, which is glutamatergic. The AC is located in the superior temporal circumvolution, or transverse temporal gyrus also known as Heschl's gyrus and is organized in the core, belt, and parabelt areas that show bidirectional connectivity. It seems that the core responds to pure tones, while belt and parabelt would respond to complex sounds and sound patterns [43]. The AC sends massive projections back to the MGN, providing a feedback control. The MGN, in turn, sends additional projections to the basal ganglia and amygdala, thus, connecting the auditory and the limbic systems, favoring the 
association of sounds with its emotional and mnemonic aspects, including fear conditioning and conditioned fear memory. The glutamatergic inputs from the MGN increase plasticity in the amygdala by LTP and increase ionotropic glutamatergic AMPA receptors [44].

The basilar membrane is organized tonotopically, that is, the tones close to each other in terms of frequency are represented topologically, one next to the other, and so all along with the other areas of the auditory pathway. Similarly, distinct tonotopic maps are located in the auditory cortex, matching that of the basilar membrane, thus representing the spectrum of audible frequencies. Here too close tones are represented by neurons close to each other, therefore specific groups of neurons are activated by sounds of different pitches or tones. The low frequencies are in the rostral/lateral position and the high frequencies in the caudal/medial position. Other areas of the cortex help to carry out the perceptual analysis of the music, the extraction of more specific information on its acoustic characteristics, such as tone, timbre, intensity, and harshness. Music, therefore, to reach the auditory cortex engages a network of subcortical regions, thalamus, amygdala, and also the nucleus accumbens, a key component of the mesolimbic dopaminergic reward system, as mentioned above. Indeed, the auditory cortex seems to have a role also in affective processing and in processing emotions from auditory information especially music. That is, it would be an emotional hub [45]. Finally, auditory perceptions reach the associative areas of the prefrontal, the orbitofrontal, and the cingulate cortex. In addition to these cortical regions, part of the motor cortex is also involved. As mentioned, the various properties of music are decoded and interpreted by different parts of the brain. The tone, which is the interval between two sounds with a defined frequency, forms the basis of the melody, of the chords (several tones playing simultaneously), and of the harmony (two or more melodies simultaneously), it is perceived by a small area in the right temporal lobe. In turn, the timbre, which distinguishes between sounds that have the same tone, and the same intensity, is decoded by another nearby center. Presumably, it is the cerebellum that processes the rhythm while the frontal lobes interpret the emotional content of the music. However, it must be emphasized that for the perception of music the interaction of activity occurs on both sides of the brain. In the right part, there are the centers for the perception of tone, melody, harmony, timbre, and rhythm, and in the left part frequency and intensity changes, both in music and in words.

In the temporal lobe are located the auditory mirror neurons that are activated when the monkey (or man) performs actions with the hand or mouth and when listening to the sound of similar actions [46]. This is a widespread neuronal system in various areas of the cortex that induce empathy, suggesting that humans, like other mammals and the birds, are incline to experience the emotions of others and to imitate the action of others. There is a tri-modal (motor, visual, and auditory) mirror 
neuron system in the monkey ventral premotor cortex that is probably similar in humans. fMRI maps have shown that the same points are activated both when the emotion was evoked by natural stimuli (e.g. rotten food) and when the subject saw - or rather "read" - the same emotion (disgust) in another. The emotions of the others are felt directly as if they were really that of the observer, their own: it is not just about imitation and understanding, but about feeling yourself as if you were the other. In this way, mirror neurons give us the faculty of identification, participation, empathy, which is so strongly evoked by music. Evolution has selected empathy as an indispensable biological resource for the survival of the species and the individuals who compose it.

It should also be considered that the centers that process visual recognition, memory, and affectivity are also located in the temporal lobe. Further down there is the hippocampus, which stores memories, therefore long-term memory. Behind the auditory cortex lays the Wernicke's area, involved in understanding written and spoken language. Recent studies confirm the localization of the Wernicke's area in the left temporal lobe, and specifically in the superior temporal gyrus, rostrally to the primary auditory cortex (also in monkeys, suggesting that language may have a common origin in primates). To appreciate music, it is probably necessary to know its language, and understand the auditory sensations, that are "screened" first by the amygdala, the limbic system and the frontal cortex thus producing the emotions that we associate with music, different sounds, and songs.

The Wernicke's area is directly connected to the Broca's area in the frontal lobe by the arcuate fasciculus, which thus allows mediating complementary aspects of language processing. The Broca's area, located in the foot of the third frontal convolution of the left hemisphere, is involved in the processing of language and is considered the word's production center. The musical notes and scales (rhythmic) are mediated primarily by the left hemisphere (Wernicke's area) and the melodies (harmoniously) are processed by the right hemisphere. fMRI studies have revealed that the areas of the human brain involved in the processing of musical information are similar to those used for language processing. The areas of Broca and Wernicke, the superior temporal sulcus, the auditory cortex, the insular cortex are all activated in subjects that listen to musical chords. Indeed, the speech too has musical intonation (prosody) and represents the affective component of the language.

Thus, Broca's area presides over the articulation of the language which can be "spoken". The word presented instead in writing first reaches the primary visual areas, in the posterior part of the occipital lobe, then passing to the front towards the motor areas. While the "tactile" words, read for 
example through the Braille method, are recognized by a tactile sensory module and then screened by the linguistic modules of the brain.

Hence, it is well established that the language depends on the areas of Wernicke and Broca connected dorsally through the arcuate fasciculus, in both hemispheres. However, recent studies in primates and humans suggest two separate pathways that connect the auditory cortex to the prefrontal areas, comparable to those of the visual system: a dorsal path (ADP), and a ventral path (AVP). The latter has connections that project anteriorly along the superior temporal gyrus. The two paths would have different roles in auditory processing, with the ventral path specialized for the recognition of familiar sounds and, in humans, of understandable language. The APD would be assigned to spatial processing or to the perception of phonemes in language, melody, and timbre in music, as well as imitation and repetition of speech and sounds. The AVP has been identified only in the left hemisphere, consistent with recent fMRI results which show that only the left hemisphere is activated in language processing [47]. The same pathways are used to process and produce music and songs. Therefore, the musical brain uses various systems that are also used for other functions. The auditory cortex in the temporal lobe is undoubtedly involved. Many clinical cases describe patients with severe temporal epilepsies in which the "musical" brain suddenly wakes up and individuals who do not know music or have ever played became passionate musicians, or on the contrary, have lost the musical skills that before they owned. In other patients, however, music can trigger epileptic seizures [6]. The western cultural tradition is also based on the negative effects of music. Starting with the listening to the abyss song of the Sirens, without getting lost like the Homeric Ulysses, which is saved only by accepting the constraints necessary to keep his distance. But he knows that the song is addressed to him and to other navigators that like "sea birds go away, never stops, because all the images carry the writing: go beyond" (Montale).

Not only, but there are also pathologies where music can have an even more negative effect, such as in pathological gambling. In many slot machines, there are strong links with sound effects, each game creates special sounds and background music that accompanies the player, who is not aware of it. Over time, a game's sound effects become primarily responsible for a player's attachment to a particular slot machine and increase dependence on gambling. Albeit little reported in medical scientific literature, patients, especially those with obsessive-compulsive disorders can present musical obsessions (also known as earworms or stuck song syndrome [SSS]) represented by repeated intrusions into the mind of sounds or songs that generate anxiety, and the patient fails to eliminate [48]. 
Both music and language involve not only the left but also the right hemisphere. In right-handed individuals the language centers are located in the left hemisphere but damage to the right hemisphere alters general aspects of language [intonations, emphasis (increase in the intensity of the voice), height]. It is the right hemisphere that distinguishes the quality of a sentence (question from affirmation, sarcasm from sincerity), that is the prosody.

Finally, it must be said that another region of the cortex that responds to sound is the insular one, which has been implicated in the ability to understand the emotional experiences of others and seems to be associated with the emotional appreciation of music in humans [49].

Sound localization has great value for the survival of an animal, but how is the sound localized? To locate sound sources, an animal compares the arrival time of the sound between the two ears, i.e. the time difference that a sound takes to reach each ear. This is the main localization signal to interpret the lateral position of a sound source. The synaptic impulses coming from the ear closest to the sound establish a map in a neuronal network that is compared with the impulses coming from the ear furthest from the sound and this calculation is performed at each frequency of the sound, using a network of neurons juxtaposed in the encephalic trunk. The difference in sound time for each ear, called the inter-auricular time difference, varies from zero (sound directly in front of the subject) to about 300 microseconds (according to the size of the head). The wavelength of the sound and its tone also help determine where it comes from. The superior olivary nucleus in the brainstem measures the time difference of arrival of sounds and the difference in sound intensity between the ears. Of course, the sight also helps to locate sounds, when it is possible to see their origin, indicating a strong match between visual and acoustic signals. The interaction goes further. For instance, when looking at a photograph associated with a sound, the auditory cortex is activated. Visual and auditory cooperation is also shown in experiments where the vision of silent images representing specific conditions of sounds, such as a saw that cuts or a dog that barks or a cup that falls to the ground and shatters, activates in our brain the same brain areas that would be activated if we heard those sounds, those noises. That is, the visual stimuli activate the brain areas that process the sounds, and the auditory cortex clicks into action. People subjected to these experiments in an anechoic chamber not only show the activity of the cortical auditory areas seen by fMRI but claimed to have heard the sounds that only the mind had reproduced. Similarly, the sounds even without seeing what produced it, activate the occipital visual cortex and, as mentioned above, the mirror neuron system.

Furthermore, singing in the mind or imagining the notes that are about to arrive requires the generation of mental images of one or more tones. Behavioral activities involving intonation 
assessments indicate that multiple memory systems contribute to the formation of accurate mental imagery. This requires the involvement of the auditory areas and related error detection circuits [50]. Although auditory imagery has positive effects on learning, reasoning, musical performance, it can also induce mental alterations, such as auditory hallucinations in schizophrenic patients [51].

\section{Songbirds}

It is definitively accepted that as humans, other animal species use vocal communication, in the form of language or music.

Amongst them are the gibbons, dolphins, whale, even bats, that use echolocation for the orientation and feeding, but also for intercepting conspecifics and thus facilitates communal attraction for reproduction. But it is amongst birds that there is the largest number of species that possess verbal communication skills, including parrots, crows, nightingales, canaries, wrens, sparrows, finches. The songbirds offer an extraordinary model for studying sound production mechanisms largely similar to humans.

The birds' brain do not show a structured neocortex as mammals. However, recent work published in Science shows that bird's extraordinary cognitive abilities, which are comparable to those of mammals, depend on a repeating columnar structure in the pallium, connected to adjacent columns and, through tangential connections, to the higher motor and associative areas. This circuit organization is similar to its mammalian counterpart and is reminiscent of the mammalian cortex [52]. In addition, another study in which two crows had to keep track of what they had seen to receive a reward, shows that the crows had a "sensory consciousness": they knew what they had seen, and this depends on the pallium [53]. From a neurobiological research point of view, the study of songbirds has the very high merit, thanks to the pioneering work of Fernando Nottebhom, for having demonstrated that neurogenesis occurs in the adult brain, thus dissipating a scientific prejudice that in the adult brain no new neurons could be born and be inserted into existing circuits (for reviews see [54] [22] [55]). This long-lasting bias, harshly sustained by distinguished neuroscientists, was based on a statement by Ramon y Cajal, wrongly taken as "dogma": "...once the development was ended, the founts of growth and regeneration of the axons and dendrites dried up irrevocably. In adult centers, the nerve paths are something fixed, ended, and immutable. Everything may die, nothing may be regenerated. It is for the science of the future to change, if possible, this harsh decree. " [56].

What is very surprising is that there is a strong analogy of the circuits and centers of speech and music between man and songbirds, yet mammals and birds on the evolutionary scale separated 
about three hundred million years ago. In learning birdsong, as for human language, auditory feedback is necessary, which takes place through circuits that involve the basal ganglia equivalents. The birds' vocal system has two main branches: the posterior descending path (PDP), or song production circuitry (HVC $\rightarrow$ RA $\rightarrow$ nXIIts $\rightarrow$ muscles of syrinx), used for the acquisition and production of the learned song, and the anterior path (AFP), song learning circuitry (HVC $\rightarrow$ Area X $\rightarrow$ DLM $\rightarrow$ LMAN $\rightarrow$ RA), which is necessary during the acquisition. The LMAN (the lateral magnocellular nucleus of the nidopallium), the output pathway of the AFP that project to the motor pathway is necessary for song variability, as shown by lesions experiments in both juvenile and adult birds. The high vocal center (HVC) is at the starting point of both the PDP and the AFP pathways. The two pathways lead to neurons of the hypoglossal nucleus (nXII) which project towards the vocal muscles. The HVC through the PDP thus projects directly to the RA nucleus (robust nucleus of the arcopallium) and indirectly through the AFP via Area X (basal ganglia portion of this pathway) to the dorsolateral anterior thalamic nucleus (DLM) and LMAN, and it can be considered homologous to the mammalian cortico-basal ganglia-thalamo-cortical loop [54]. In mammals within the nuclei of the basal ganglia, the striatum receives glutamatergic innervation from the cerebral cortex and thalamus. The medium spiny striatal neurons are GABAergic and project on the internal segment of the globus pallidus (GPi) and on the substantia nigra pars reticulata. These nuclei, in turn, contain GABAergic neurons that project onto the thalamus. This "direct path" inhibits the GPi and the SNr, causing disinhibition of the network or excitation of the thalamus, facilitating motor actions.

In the dorsal striatum originates the indirect path, which inhibits the external segment of the globus pallidus (GPe), with consequent disinhibition of the GPi that in turn inhibits the thalamus.

Another shorter indirect path involves the cortical excitation of the glutamatergic neurons of the subthalamic nucleus with consequent direct excitation of the GPi and the inhibition of the thalamus. Both indirect pathways lead to global motor inhibition.

These pathways are fundamental for learning the motor sequence and they are similar in songbirds where the AFP regulates the goal-directed behavior of song learning. Indeed, the avian auditory pallium, which is not layered as the mammalian cortex, exhibits the same information-processing principles as cortical microcircuit [57].

In songbirds, the song has structural (minimum unit, phrase, song) and physiological (brain circuits) characteristics and vocal performance in common with human language and music [58]. Their repertoire is extraordinarily rich and variable, as human language and music. A nightingale (Luscinia megarhynchos) can sing up to 200 different songs. Charles Darwin was so struck by the 
enchanting effects of songbird melodies on humans, that in 1871 he wrote in The Descent of Man: "The sounds uttered by birds offer in several aspects the nearest analogy to language, for all the members of the same species utter the same instinctive cries expressive of their emotions; and all kinds that have the power of singing exert this power instinctively". In songbirds, vocalization is accomplished through several complex brain circuits, it is learned by imitating that of adult members (tutors) of the same species, and over time new neurons occupy specific places in the circuits necessary for learning to sing, without the birth of these new neurons and their integration into the pre-existing circuits learning of singing and/or new "melodies" are not realized.

Bird song, therefore, offers a formidable model for studying the neural and molecular mechanisms of auditory-vocal learning. Furthermore, recent research suggests the possibility of parallels with human vocalization or musical production at the syntax level [59]. However, birds have a limited ability to construct phrases, that is, they are able to organize only a limited number of calls in particular ways and this may not allow them to create new meanings, in other words, they have a limited ability to construct phrases [58]. Songbirds learn to vocalize much like human infants when they acquire spoken language: the learning of the song begins with disconnected sounds, called subsongs, similar to the babbling of the human child. Birds languages have rules like in humans but there is an increase in complexity and abstraction unique in humans. Interestingly, most songbirds sing using intervals like in human music - octaves, perfect fifths, and perfect fourths.

The vocal apparatus of birds is the syrinx, equivalent to the human larynx. Six pairs of syrinx muscles control the frequency and amplitude of the sound flexibly and independently. Songbirds can sing with two independent voices by controlling the right and left halves of the syrinx separately.

Songbirds have brain regions analogous to the Broca's area (the HVC) and the Wernicke's area (the caudomedial nidopallium), which show a similar dissociation between vocal production and auditory perception and memory. These centers are also asymmetrical and lateralized like those of human language, mainly in the left hemisphere [60]. Songbirds like humans learn their vocalizations. As in humans, social interactions are fundamental for the acquisition of speech and language in birds because they too learn their vocalizations during postnatal development.

Interestingly, the mothers of some birds (e.g. Australian superb fairy-wrens, Malurus cyaneus) sing softly to their eggs. Chicks can listen to their mothers and learn elements of her songs while inside the egg. This is a typical song, a sort of a family signature, that allows parents to recognize their offspring and exclude youngsters hatched from eggs that parasitic nestling birds (such as cuckoo, which does not build nests) may have inserted within the wren's nest. Also, this sort of family call 
is retained by the bird in its adult age and becomes an acoustic signature for kin recognition, so individuals can be identified as relatives that receive preferential information about food availability, allows collective detection of predators, and also avoid inbreeding [61].

Young birds receive feedback from adults, which seems central to the improvement of song learning. It must be said that adult male zebra finches, for instance, change the structure of their song when teaching young birds, a bit like when humans change the tone and speech when talking to babies and small children. The songs have longer pauses between the motifs, are more repetitive, and are composed of more structured syllables. And there is a complex interaction between pupils and tutors. Generally speaking, vocal learning involves sensory learning and sensorimotor learning. Young songbirds first memorize the tutor's song (sensory learning). Then, they perfect their vocalizations by repetition until they come close to reproducing those memorized, and when they are adults, they can produce a song very similar to the one taught by the tutor. Instead, individuals raised in isolation cannot reproduce mature and typical vocalizations of the species as adults. As in humans when they listen to the music they love, the reward system is activated in the female birds that listen to the singing of the males.

Another point of convergence of birdsong and human language is given by the FOXP2 transcription factor, abundantly expressed in the circuits of sound production in the two species. Mutations of this gene in humans have been related to a form of dyspraxia and the ablation of this gene in birds prevents these animals from learning to sing [62] [58] [63]). The human FOXP2 gene differs slightly from that of other species and its function is indispensable for language and singing. Transgenic mice that express the human gene become capable of deeper vocalizations than normal controls, suggesting that FOXP2 is involved in the development of the brain circuits that underlie the movements of vocalization used in language [64]. Also, song induces ERG-1(Early growth response protein 1, or cFos, or Zenk) mRNA and protein expression within both anterior and posterior forebrain pathways and in female hearing appealing songs [65]. EGR-1 is a zinc-finger DNAbinding transcription factor that can function as an activator or repressor of target gene transcription. It is now well known that noncoding RNAs, including miRNA, play an important role in CNS activity and gene regulation, including the reward system, in humans and birds. Several miRNAs have been involved in the regulation of Area X in birds and the dopaminergic/basal ganglia system in humans, including miR-9, whose dysregulation alters learning and singing in zebra finches, and in humans, it can compromise language, and these alterations correspond to downregulation of FOXP1 and FOXP2 [66]. Equally, miR-34b/c is involved in dopaminergic neuron development and thus in the regulation of the reward system [67]. 
Despite the common assumption that only male songbirds sing, it has been proven that also females of these species sing [68]. However, it is worth noticing that in the control nuclei of the song there is a sexual dimorphism dependent on androgens and estrogens. Testosterone doubles the volume of the HVC nucleus in canary females and they begin to sing like males. New neurons are added to this process. As previously mentioned, new neurons are constantly being added to the brains of males in new seasons. In fact, during autumn the HVC loses neurons and new neurons are added in the next spring period. It turns out that this neurogenesis is necessary for male canaries to develop a new repertoire of songs every year.

Finally, like humans, birds can also generate sounds using instruments, substrates that can be a tree, as for the woodpecker, or particular feathers, as for the woodcock, even if most of the sounds are produced by the syringes.

\section{Music Therapy}

Since ancient times, it has been speculated that music may have therapeutic value. The ancient Egyptians describe musical spells to cure the sick. The Greek god Apollo was the deity of music, arts, and medicine. According to the myth, he played the lyre, invented the lute, and was associated with health and healing. Greek doctors used wind or string musical instruments to treat their patients. Aristotle claimed that flute music could purify the soul by arousing strong emotions. In modern times, in England the apothecary Richard Brown in his book Medica Medicina (1729) then Richard Brocklesby in the 1749 treatise Reflections on the Power of Musick sustained music's therapeutic potential for illnesses and that music can exert an effect on both the mind and the body, based on scientific experimental approaches, arguing against myths. But the first experimental studies were conducted by the French physician Diogel (late 1700) who, by bringing musicians to the bedside of his patients, demonstrated that music can lower blood pressure, increase cardiac output, decrease heart rate.

Music, listened or performed, is now a day used in various therapeutic approaches. Music therapy can become a powerful tool to enhance neuroplasticity in the brain and to improve the quality of life of patients with a damaged nervous system.

Numerous rehabilitation interventions for patients suffering from various neurological diseases (dementia, Parkinson's disease, stroke, epilepsy, and multiple sclerosis) demonstrate that music therapy can improve social interactions, reduce anxiety and agitation, thus improving the quality of life, especially in people with moderate dementia.

Furthermore, music therapy is successfully used in post-traumatic rehabilitation, and patients suffering from autism, behavior disorders, anxiety states, coma, Alzheimer's disease. For example, in 
brain stroke patients, listening to a couple of hours of music a day has a positive effect not only on the mood but also on the ability to recover both verbal memory and attention. A study conducted on older people suffering from cognitive decline shows that both meditation and listening to music improve mood and well-being and mitigate stress [69].

Parkinson's patients can improve their walking with the help of music.

Music-induced chills engender reduced activity in brain structures associated with anxiety circuitry such as the amygdala, the dorsal anterior cingulate cortex that amplifies, and the ventromedial prefrontal cortex that reduces fear signals coming from the amygdala [70] [71].

The use of music in the treatment of psychiatric and neurological disorders is founded on the present knowledge that it can modulate activity in the brain structures involved in emotion [72]; [73].

Particular attention has been paid in the last decades to the effects of music in young people and adults with autism spectrum disorder (ASD). These researches have been prompted by the findings that in people with ASD listening to music improves musical memory, the perception of tones and sound frequencies, and emotions. Adults with ASD while listening to the music show the activation of reward circuits and emotions including NAcc, VTA, striatum, amygdala, prefrontal, and orbitofrontal cortex. In ASD patients, music therapy improves social, communication, and emotional skills [74]. However, compelling evidence for the effectiveness of music therapy in various diseases is mixed in the literature.

While the music could be used to heal brains, Dan Lloyd and collaborators have shown that it is possible to transduce the images of brain activity obtained through fMRI into sounds, allowing us to listen to the complexity of brain activity, which he says, is structured musically, it seems that brain activity corresponds to that of an orchestra [75]. Comparing the "music" generated from fMRI of the brains of some schizophrenic patients with that obtained from brain scans of healthy controls, are apparent unusual oscillations in distributed networks in these patients. Transposition of brain scans into music can, therefore, reveal differences and similarities between healthy and dysfunctional brain. Thus, this approach could be a useful diagnostic tool. In other words, while music can cure the brain, brain activity in music can help diagnose neurological and psychiatric diseases. Yet, these conclusions are highly debated.

These observations isolate suggest that music may have wider applications in therapy. That is, it is hoped that music will prove to be a non-invasive way to involve an alleged innate ability of the brain to heal itself. Furthermore, how music modulates the brain's response to damage can illustrate 
some aspects of neuroplasticity, the ability of the nervous system to reshape and reorganize itself in response to environmental events.

However, there are too few large-scale, randomized control studies, except for example a few with patients with dementia where active group singing has proven to be a potentially effective nonpharmacological intervention to improve the quality of life of these patients, but in specific contexts. However, we believe that it is necessary to recommend considerable caution in the use of listening to music in patients in a coma or with impaired consciousness, as well as in patients with autism or with severe dementia, because, at present, there is a considerable lack of evidence of reproducible results. To exploit the potential of music therapy are needed further studies to evaluate its efficacy, training of specialized academic and clinical personnel, defining accurate methodologies and careful selection of intervention techniques to fit the needs of the patients are essential [76].

\section{Music and Altruism}

Finally, it is interesting to evaluate how positive or negative music-induced states affect our behavior. Recent studies show that music we like can make us more altruistic, while music we dislike can make us more selfish. Altruistic behavior is defined as inclination or love of neighbor, respectful of the feelings of others, which results in active participation in the resolution of problems, difficulties, needs of others, sometimes with self-denial, up to the sacrifice of one's life.

That is behaviors intended to help other people with no reward expected, and sometimes some sort of risk or cost to the self. These responses promote our ability to flourish as a community. We have shown that listening to some musical phrases move us, evoke images and dreams. Music can be a means by which people can cope with emotions, conflicts, increase their self-awareness, and mediate several behaviors related tangentially to altruism. If indeed human altruism is engendered by empathy [77], since music activates empathy circuits it would be expected to increase altruistic actions. Indeed, music and musical relationships are to be considered by themselves as a gift, and thus altruistic. Music has a stabilizing function in interacting with other human beings, thus also resulting in a survival value [78][79].

Indeed, the same areas of the brain (nucleus accumbens, anterior cingulate cortex, and regions in the prefrontal cortex) are active when performing mutually cooperative tasks and when listening to music that reinforces empathy and induces sharing emotions. Oxytocin hormone levels are also increased during music production, as mentioned above, and in promoting cooperative or altruistic behaviors. Music also enhances the ethics of philanthropy. Already Handel in the mid-eighteen century set annual performances to support an orphans' charity in London. In most modern times 
large-scale benefit concert, as the Concert for Bangladesh, in 1971, and Live Aid in 1985, brought experiences that unite viewers with one another and their societies, as exampled by the song "We are the world", which soon became a hymn, speaking of brotherhood, love, and solidarity.

\section{Conclusions}

Overall, the neural networks responsible for processing music are widely distributed within the brain. The combination of widespread activation of motor and cognitive systems, including memory, together with the concomitant recruitment of limbic circuits, which are associated with emotions and reward, or more generally, the commitment of multiple cognitive functions and neural circuits, could constitute the distinctive character of the responses induced by music and contribute to their peculiar subjective richness. Based on these specific activations of many brain circuits, music has the power to elicit strong and different emotions, and emotions are widely involved in the enjoyment of music.

However, emotion is only one aspect of musical communication, even if music can express emotions in an extremely powerful way. Music also communicates movement, it allows people to synchronize their movements and thus create a strong sense of group, a group consciousness. There are, thus, many ways in which music can effectively communicate and establish synchronization and resonance between brains and therefore people, between musicians and between musicians and listeners.

Music is thus a means for socialization, a means that can help to overcome egocentrism, managing to understand the needs of the group and to learn to listen to the others and what they propose. Making music ensemble has great value: it helps to understand the importance of respecting others and the meaning of living in harmony with the rest of the group. If there is no cooperation, if there is no listening, if there is no respect and collaboration, the ensemble group does not work, it is as if everyone were following a different score performed simultaneously, resulting in total chaos. Music is union, complicity, and respect.

In summary, recent studies show that music is an important form of communication, not uniquely human. Several other species use music as a language amongst which many birds. In particular, songbirds, which share many aspects of the musical system and music learning with humans. Music has been a drive of human brain evolution and a sort of glue in early human society, and it thought to have played an important role in social aggregation. It elicits memories, emotions, feelings, changing the chemistry of the brain, and it can open new avenues to alleviate, if not cure, severe illness, especially neurological and psychiatric. Musical sounds in humans are highly rewarding through predictive processes in the brain's pleasure networks, including activation of the 
dopaminergic mesolimbic system. Favorite music can also promote altruistic behaviors which are an empathic product, probably mediated by mirror neurons. Finally, there are many pro-social benefits from listening to music.

However, many aspects of the neural substrates affective/emotional, synchronization and resonance categories, generated by music, the genes involved, and the epigenetic scenario that regulates them, have still to be elucidated. Therefore, exciting new possibilities remain open for future research on music and the brain.

"The man that hath no music in himself, Nor is not moved with concord of sweet sounds, Is fit for treasons, stratagems, and spoils; The motions of his spirit are dull as night, And his affections dark as Erebus. Let no such man be trusted. Mark the music", Shakespeare, The Merchant of Venice 
Author Contributions: Conceptualization, UdP and LS. writing — original draft preparation, UdP; writing — review and editing, LS; supervision, UdP and LS-

All authors have read and agreed to the published version of the manuscript.

Funding: This work received no external funding.

Conflicts of Interest: The authors declare no conflict of interest, nor competing interests. 


\section{Legend to figures}

Fig. 1. Shubert's sonata To Music

A page of the music score of Schubert's sonata op. 88 no. 4

Fig. 2 The areas of the human brain involved in music

Most parts of the human brain are involved in performing or listening to music. In the frontal lobe, implied in thinking, decision-making and planning, is located the Broca's are, which enables us to produce speech and to express music, and the prefrontal cortex, necessary for production and learning of music; in the temporal lobe, which processes what we hear, where reside the auditory cortex and the Wernicke's Area, necessary to comprehends written and spoken language and to analyze and enjoy music; the occipital lobe, or the visual cortex, is used by musicians when listening to music, probably because they visualize the musical score, while listeners use the temporal lobe, i.e. the auditory and language center; the basal ganglia, which are part of the reward system that is triggered by dopamine, which comprises the nucleus accumbens, the putamen that processes rhythm and regulates body movement and coordination, and the amygdala, the almondshaped structure that processes and triggers emotions, controls fear, and increases pleasure; the hippocampus, the seahorse-shaped structure that produces and retrieves memories, regulates emotional responses, where intense neurogenesis takes place in the adult brain and is increased by music; the hypothalamus (not shown in the picture), which produces and releases essential hormones amongst which oxytocin and vasopressin (see text). 


\section{References}

1. Mithen, S. The Singing Neanderthals: The Origins of Music, Language, Mind and Body. London : Weidenfeld and Nicolson, 2005.

2. Flashmob Beethoven Symphony No.9. 2012.

3. Yurgil, K.A.; Velasquez, M.A.; Winston, J.L.; Reichman, N.B.; Colombo, P.J. Music Training, Working Memory, and Neural Oscillations: A Review. Front Psychol 2020, 11, 266, doi:10.3389/fpsyg.2020.00266.

4. Byrne, D. How music works. San Francisco [Calif.] : McSweeney's.

5. Carannante. Piscina Mirabilis - in Spare Parts Sound Project. 2014.

6. Sacks, O.W. Musicophilia : Tales of Music and the Brain. Knopf Doubleday Publishing Group: 2007.

7. Zhang, Y.; Chen, G.; Wen, H.; Lu, K.H.; Liu, Z. Musical Imagery Involves Wernicke's Area in Bilateral and Anti-Correlated Network Interactions in Musicians. Sci Rep 2017, 7, 17066, doi:10.1038/s41598-017-17178-4.

8. Mehr, S.A.; Singh, M.; York, H.; Glowacki, L.; Krasnow, M.M. Form and Function in Human Song. Curr Biol 2018, 28, 356-368.e355, doi:10.1016/j.cub.2017.12.042.

9. Egermann, H.; Fernando, N.; Chuen, L.; McAdams, S. Music induces universal emotion-related psychophysiological responses: comparing Canadian listeners to Congolese Pygmies. Front Psychol 2014, 5, 1341, doi:10.3389/fpsyg.2014.01341.

10. Huang, H. Why Chinese People Play Western Classical Music: Transcultural Roots of Music Philosophy. International Journal of Music Education, 2011.

11. Geissman, T. Gibbons - The singing apes. Anthropologisches Institut und Museum der Universität Zürich und Gibbon Conservation Alliance, Zürich, 48 pp., 2014.

12. Darwin. The Descent of Man, and selection in relation to sex. In two volumes. With illustrations. John Murray: 1871.

13. Kendon, A. Reflections on the "gesture-first" hypothesis of language origins. Psychon Bull Rev 2017, 24, 163170, doi:10.3758/s13423-016-1117-3.

14. Mithen, S.J. Music and the origin of modern humans. McDonald Institute: Cambridge, 2007; pp pp. 107-117.

15. Mithen, S. The music instinct: the evolutionary basis of musicality. Ann N Y Acad Sci 2009, 1169, 3-12, doi:10.1111/j.1749-6632.2009.04590.x.

16. Haueisen, J.; Knösche, T.R. Involuntary motor activity in pianists evoked by music perception. J Cogn Neurosci 2001, 13, 786-792, doi:10.1162/08989290152541449.

17. Munno, D.W.; Syed, N.I. Synaptogenesis in the CNS: an odyssey from wiring together to firing together. $J$ Physiol 2003, 552, 1-11, doi:10.1113/jphysiol.2003.045062.

18. Urwyler, O.; Izadifar, A.; Vandenbogaerde, S.; Sachse, S.; Misbaer, A.; Schmucker, D. Branch-restricted localization of phosphatase Prl-1 specifies axonal synaptogenesis domains. Science 2019, 364, doi:10.1126/science.aau9952.

19. di Porzio, U. A bigger brain for a more complex environment. Rev Neurosci 2020, doi:10.1515/revneuro-20200041.

20. Janata, P. The neural architecture of music-evoked autobiographical memories. Cereb Cortex 2009, 19, 25792594, doi:10.1093/cercor/bhp008.

21. Giedd, J.N.; Blumenthal, J.; Jeffries, N.O.; Castellanos, F.X.; Liu, H.; Zijdenbos, A.; Paus, T.; Evans, A.C.; Rapoport, J.L. Brain development during childhood and adolescence: a longitudinal MRI study. Nat Neurosci 1999, 2, 861-863, doi:10.1038/13158.

22. Colucci-D'Amato, L.; di Porzio, U. Neurogenesis in adult CNS: from denial to opportunities and challenges for therapy. Bioessays 2008, 30, 135-145, doi:10.1002/bies.20703.

23. Bellenchi, G.C.; Volpicelli, F.; Piscopo, V.; Perrone-Capano, C.; di Porzio, U. Adult neural stem cells: an endogenous tool to repair brain injury? J Neurochem 2013, 124, 159-167, doi:10.1111/jnc.12084.

24. Kuffler, S.W.; Nicholls, J.G. FROM NEURON TO BRAIN: A CELLULAR APPROACH TO THE FUNCTION OF THE NERVOUS SYSTEM. Sinauer Associates Inc., Sunderland, Massachusetts: 1976.

25. Nykjaer, A.; Willnow, T.E.; Petersen, C.M. p75NTR--live or let die. Curr Opin Neurobiol 2005, 15, 49-57, doi:10.1016/j.conb.2005.01.004.

26. Riedl, S.J.; Salvesen, G.S. The apoptosome: signalling platform of cell death. Nat Rev Mol Cell Biol 2007, 8, 405-413, doi:10.1038/nrm2153.

27. Hollville, E.; Romero, S.E.; Deshmukh, M. Apoptotic cell death regulation in neurons. FEBS J 2019, 286, 3276-3298, doi:10.1111/febs.14970.

28. Ramón y Cajal, S. Textura del sistema nervioso del hombre y de los vertebrados. Madrid : Imprenta y Librería de Nicolás Moya,: Madrid, 1899.

29. Owren, M.J. Acoustic classification of alarm calls by vervet monkeys (Cercopithecus aethiops) and humans (Homo sapiens): II. Synthetic calls. J Comp Psychol 1990, 104, 29-40, doi:10.1037/0735-7036.104.1.29. 
30. Furuyama, T.; Kobayasi, K.I.; Riquimaroux, H. Acoustic characteristics used by Japanese macaques for individual discrimination. J Exp Biol 2017, 220, 3571-3578, doi:10.1242/jeb.154765.

31. Koda, H.; Nishimura, T.; Tokuda, I.T.; Oyakawa, C.; Nihonmatsu, T.; Masataka, N. Soprano singing in gibbons. Am J Phys Anthropol 2012, 149, 347-355, doi:10.1002/ajpa.22124.

32. Gibbons sing in duet. Youtube: 2011.

33. Savage, P.E.; Loui, P.; Tarr, B.; Schachner, A.; Glowacki, L.; Mithen, S.; Fitch, W.T. Music as a coevolved system for social bonding. Behav Brain Sci 2020, 1-42, doi:10.1017/S0140525X20000333.

34. Conard, N.J. A female figurine from the basal Aurignacian of Hohle Fels Cave in southwestern Germany. Nature 2009, 459, 248-252, doi:10.1038/nature07995.

35. Salimpoor, V.N.; Benovoy, M.; Larcher, K.; Dagher, A.; Zatorre, R.J. Anatomically distinct dopamine release during anticipation and experience of peak emotion to music. Nat Neurosci 2011, 14, 257-262, doi:10.1038/nn.2726.

36. Chanda, M.L.; Levitin, D.J. The neurochemistry of music. Trends Cogn Sci 2013, 17, 179-193, doi:10.1016/j.tics.2013.02.007.

37. Wang, H.; Duclot, F.; Liu, Y.; Wang, Z.; Kabbaj, M. Histone deacetylase inhibitors facilitate partner preference formation in female prairie voles. Nat Neurosci 2013, 16, 919-924, doi:10.1038/nn.3420.

38. Ferreri, L.; Mas-Herrero, E.; Zatorre, R.J.; Ripollés, P.; Gomez-Andres, A.; Alicart, H.; Olivé, G.; MarcoPallarés, J.; Antonijoan, R.M.; Valle, M., et al. Dopamine modulates the reward experiences elicited by music. Proc Natl Acad Sci U S A 2019, 116, 3793-3798, doi:10.1073/pnas.1811878116.

39. Peterson, R.J.; Safer, M.A.; Jobes, D.A. The impact of suicidal rock music lyrics on youth: an investigation of individual differences. Arch Suicide Res 2008, 12, 161-169, doi:10.1080/13811110701857533.

40. Mallik, A.; Chanda, M.L.; Levitin, D.J. Anhedonia to music and mu-opioids: Evidence from the administration of naltrexone. Sci Rep 2017, 7, 41952, doi:10.1038/srep41952.

41. Bayer, H.M.; Glimcher, P.W. Midbrain dopamine neurons encode a quantitative reward prediction error signal. Neuron 2005, 47, 129-141, doi:10.1016/j.neuron.2005.05.020.

42. Haber, S.N. Neuroanatomy of Reward: A View from the Ventral Striatum. Neurobiology of Sensation and Reward. Boca Raton (FL): CRC Press/Taylor \& Francis. Chapter 11. Gottfried JA, editor 2011.

43. Nourski, K.V.; Steinschneider, M.; McMurray, B.; Kovach, C.K.; Oya, H.; Kawasaki, H.; Howard, M.A. Functional organization of human auditory cortex: investigation of response latencies through direct recordings. Neuroimage 2014, 101, 598-609, doi:10.1016/j.neuroimage.2014.07.004.

44. Park, S.; Lee, J.; Park, K.; Kim, J.; Song, B.; Hong, I.; Lee, S.; Choi, S. Sound tuning of amygdala plasticity in auditory fear conditioning. Sci Rep 2016, 6, 31069, doi:10.1038/srep31069.

45. Koelsch, S. A coordinate-based meta-analysis of music-evoked emotions. Neuroimage 2020, 223, 117350 , doi:10.1016/j.neuroimage.2020.117350.

46. Gazzola, V.; Aziz-Zadeh, L.; Keysers, C. Empathy and the somatotopic auditory mirror system in humans. Curr Biol 2006, 16, 1824-1829, doi:10.1016/j.cub.2006.07.072.

47. Parker, G.J.; Luzzi, S.; Alexander, D.C.; Wheeler-Kingshott, C.A.; Ciccarelli, O.; Lambon Ralph, M.A. Lateralization of ventral and dorsal auditory-language pathways in the human brain. Neuroimage 2005, 24, 656-666, doi:10.1016/j.neuroimage.2004.08.047.

48. Euser, A.M.; Oosterhoff, M.; van Balkom, I. Stuck song syndrome: musical obsessions - when to look for OCD. Br J Gen Pract 2016, 66, 90, doi:10.3399/bjgp16X683629.

49. Gujing, L.; Hui, H.; Xin, L.; Lirong, Z.; Yutong, Y.; Guofeng, Y.; Jing, L.; Shulin, Z.; Lei, Y.; Cheng, L., et al. Increased Insular Connectivity and Enhanced Empathic Ability Associated with Dance/Music Training. Neural Plast 2019, 2019, 9693109, doi:10.1155/2019/9693109.

50. Janata, P. Acuity of mental representations of pitch. Ann N Y Acad Sci 2012, 1252, 214-221, doi:10.1111/j.1749-6632.2011.06441.x.

51. Agnati, L.F.; Barlow, P.; Ghidoni, R.; Borroto-Escuela, D.O.; Guidolin, D.; Fuxe, K. Possible genetic and epigenetic links between human inner speech, schizophrenia and altruism. Brain Res 2012, 1476, 38-57, doi:10.1016/j.brainres.2012.02.074.

52. Stacho, M.; Herold, C.; Rook, N.; Wagner, H.; Axer, M.; Amunts, K.; Güntürkün, O. A cortex-like canonical circuit in the avian forebrain. Science 2020,369, doi:10.1126/science.abc5534.

53. Nieder, A.; Wagener, L.; Rinnert, P. A neural correlate of sensory consciousness in a corvid bird. Science 2020, 369, 1626-1629, doi:10.1126/science.abb1447.

54. Nottebohm, F. The neural basis of birdsong. PLoS Biol 2005, 3, e164, doi:10.1371/journal.pbio.0030164.

55. Owji, S.; Shoja, M.M. The History of Discovery of Adult Neurogenesis. Clin Anat 2020, 33, 41-55, doi:10.1002/ca.23447.

56. Ramon y Cajal, S. Degeneration and Regeneration of the Nervous System. Oxford University Press, London 
57. Calabrese, A.; Woolley, S.M. Coding principles of the canonical cortical microcircuit in the avian brain. Proc Natl Acad Sci U S A 2015, 112, 3517-3522, doi:10.1073/pnas.1408545112.

58. Bolhuis, J.J.; Okanoya, K.; Scharff, C. Twitter evolution: converging mechanisms in birdsong and human speech. Nat Rev Neurosci 2010, 11, 747-759, doi:10.1038/nrn2931.

59. Suzuki, T.N.; Wheatcroft, D.; Griesser, M. Experimental evidence for compositional syntax in bird calls. Nat Commun 2016, 7, 10986, doi:10.1038/ncomms10986.

60. Moorman, S.; Gobes, S.M.; Kuijpers, M.; Kerkhofs, A.; Zandbergen, M.A.; Bolhuis, J.J. Human-like brain hemispheric dominance in birdsong learning. Proc Natl Acad Sci U S A 2012, 109, 12782-12787, doi:10.1073/pnas.1207207109.

61. Colombelli-Négrel, D.; Hauber, M.E.; Robertson, J.; Sulloway, F.J.; Hoi, H.; Griggio, M.; Kleindorfer, S. Embryonic learning of vocal passwords in superb fairy-wrens reveals intruder cuckoo nestlings. Curr Biol 2012, 22, 2155-2160, doi:10.1016/j.cub.2012.09.025.

62. Konopka, G.; Bomar, J.M.; Winden, K.; Coppola, G.; Jonsson, Z.O.; Gao, F.; Peng, S.; Preuss, T.M.; Wohlschlegel, J.A.; Geschwind, D.H. Human-specific transcriptional regulation of CNS development genes by FOXP2. Nature 2009, 462, 213-217, doi:10.1038/nature08549.

63. Lai, C.S.; Fisher, S.E.; Hurst, J.A.; Vargha-Khadem, F.; Monaco, A.P. A forkhead-domain gene is mutated in a severe speech and language disorder. Nature 2001, 413, 519-523, doi:10.1038/35097076.

64. Enard, W.; Gehre, S.; Hammerschmidt, K.; Hölter, S.M.; Blass, T.; Somel, M.; Brückner, M.K.; Schreiweis, C.; Winter, C.; Sohr, R., et al. A humanized version of Foxp2 affects cortico-basal ganglia circuits in mice. Cell 2009, 137, 961-971, doi:10.1016/j.cell.2009.03.041.

65. Monbureau, M.; Barker, J.M.; Leboucher, G.; Balthazart, J. Male song quality modulates c-Fos expression in the auditory forebrain of the female canary. Physiol Behav 2015, 147, 7-15, doi:10.1016/j.physbeh.2015.04.005.

66. Shi, Z.; Piccus, Z.; Zhang, X.; Yang, H.; Jarrell, H.; Ding, Y.; Teng, Z.; Tchernichovski, O.; Li, X. miR-9 regulates basal ganglia-dependent developmental vocal learning and adult vocal performance in songbirds. Elife 2018, 7, doi:10.7554/eLife.29087.

67. De Gregorio, R.; Pulcrano, S.; De Sanctis, C.; Volpicelli, F.; Guatteo, E.; von Oerthel, L.; Latagliata, E.C.; Esposito, R.; Piscitelli, R.M.; Perrone-Capano, C., et al. miR-34b/c Regulates Wnt1 and Enhances Mesencephalic Dopaminergic Neuron Differentiation. Stem Cell Reports 2018, 10, 1237-1250, doi:10.1016/j.stemcr.2018.02.006.

68. Odom, K.J.; Hall, M.L.; Riebel, K.; Omland, K.E.; Langmore, N.E. Female song is widespread and ancestral in songbirds. Nat Commun 2014, 5, 3379, doi:10.1038/ncomms4379.

69. Innes, K.E.; Selfe, T.K.; Khalsa, D.S.; Kandati, S. Meditation and Music Improve Memory and Cognitive Function in Adults with Subjective Cognitive Decline: A Pilot Randomized Controlled Trial. J Alzheimers Dis 2017, 56, 899-916, doi:10.3233/JAD-160867.

70. Robinson, O.J.; Krimsky, M.; Lieberman, L.; Allen, P.; Vytal, K.; Grillon, C. Towards a mechanistic understanding of pathological anxiety: the dorsal medial prefrontal-amygdala 'aversive amplification' circuit in unmedicated generalized and social anxiety disorders. Lancet Psychiatry 2014, 1, 294-302, doi:10.1016/S2215-0366(14)70305-0.

71. Motzkin, J.C.; Philippi, C.L.; Wolf, R.C.; Baskaya, M.K.; Koenigs, M. Ventromedial prefrontal cortex is critical for the regulation of amygdala activity in humans. Biol Psychiatry 2015, 77, 276-284, doi:10.1016/j.biopsych.2014.02.014.

72. Koelsch, S. Brain correlates of music-evoked emotions. Nat Rev Neurosci 2014, 15, 170-180, doi:10.1038/nrn3666.

73. Koelsch, S. Music-evoked emotions: principles, brain correlates, and implications for therapy. Ann N Y Acad Sci 2015, 1337, 193-201, doi:10.1111/nyas.12684.

74. Quintin, E.M. Music-Evoked Reward and Emotion: Relative Strengths and Response to Intervention of People With ASD. Front Neural Circuits 2019, 13, 49, doi:10.3389/fncir.2019.00049.

75. Lloyd, D. Mind as music. Front Psychol 2011, 2, 63, doi:10.3389/fpsyg.2011.00063.

76. Rollnik, J.D.; Altenmüller, E. Music in disorders of consciousness. Front Neurosci 2014, 8, 190, doi:10.3389/fnins.2014.00190.

77. Silk, J.B.; House, B.R. Evolutionary foundations of human prosocial sentiments. Proc Natl Acad Sci U S A 2011, 108 Suppl 2, 10910-10917, doi:10.1073/pnas.1100305108.

78. Perrone-Capano, C.; Volpicelli, F.; di Porzio, U. Biological bases of human musicality. Rev Neurosci 2017, 28, 235-245, doi:10.1515/revneuro-2016-0046.

79. Volpicelli, F.; Perrone-Capano, C.; di Porzio, U. The tuned brain. S\&F n.9_2018: 2018. 